\title{
PROPRIEDADE PSICOLÓGICA, PODER E INTENÇÃO DE COMPARTILHAR CONHECIMENTO NAS ORGANIZAÇÕES
}

PSYCHOLOGICAL OWNERSHIP, POWER AND INTENTION

TO SHARE KNOWLEDGE IN ORGANIZATIONS

Recebido em 11.09.2015. Aprovado em 21.10.2016

Avaliado pelo sistema double blind review

Fernanda Pauletto D'Arrigo

DOI: http://dx.doi.org/10.12712/rpca.v10i4.688

fernanda.darrigo@gmail.com

Universidade de Caxias do Sul (UCS), Caxias do Sul/RS, BRASIL

\section{Ana Virginia Albercini Giordani Bertolini}

na_vgiordani@hotmail.com

Universidade de Caxias do Sul (UCS), Caxias do Sul/RS, BRASIL

\section{Claudia Prantz}

cprantz@gmail.com

Universidade de Caxias do Sul (UCS), Caxias do Sul/RS, BRASIL

\section{Eric Charles Dorion}

echdorion@gmail.com

Universidade de Caxias do Sul (UCS), Caxias do Sul/RS, BRASIL

\section{Resumo}

O ambiente organizacional é cenário para o desenvolvimento de inúmeras relações de poder. O sentimento de poder pode estar relacionado à posição ocupada, a influência sobre os demais, além do conhecimento sobre os produtos, processos e rotinas da organização. O fato de deter conhecimento gera o sentimento de poder na organização e com isso, compartilhar este conhecimento pode criar a sensação de perda do poder. Por isso, o objetivo deste trabalho foi identificar a influência da propriedade psicológica na intenção de compartilhar este conhecimento com os demais membros e o sentimento de poder do indivíduo na organização. Para identificar tal influência, a pesquisa possui abordagem quantitativa descritiva e ouviu 89 diretores de uma associação de jovens empreendedores da região da Serra Gaúcha, no Rio Grande do Sul. A análise dos dados indica que a propriedade psicológica do conhecimento afeta a intenção de compartilhar conhecimento tácito e explícito com os demais membros da organização.

Palavras-chave: Propriedade psicológica do conhecimento. Intenção de compartilhar conhecimento. Poder; Jovens empreendedores.

\begin{abstract}
The organizational environment is the setting for the development of several relations of power. The feeling of power can be related to the occupied position, influence on others, besides the knowledge about products, processes, and routines of the organization. The fact of holding knowledge generates the feeling of power in the organization and thus, share this knowledge can create the feeling of loss of power. Therefore, the aim of this study was to identify the influence of psychological ownership in intention to share this knowledge with the other members and the feeling of power of the individual in the organization. To identify such influence, we used the descriptive quantitative approach, to collect data from 89 directors of an association of young entrepreneurs in the Serra Gaucha - Rio Grande do Sul. The data analysis indicates that psychological ownership of knowledge affects the intention to share knowledge tacit and explicit with the other members of the organization.
\end{abstract}

Keywords: Knowledge psychological ownership; Knowledge sharing intention; Power; Young entrepreneurs 


\section{Introdução}

O comportamento dos indivíduos nas organizações tem sido alvo de discussões acadêmicas na área da psicologia e da administração, tendo como marco os estudos de Pavlov e Watson, dando espaço à Teoria Comportamentalista, que inicialmente retrata um comportamento como uma resposta a um estímulo específico. A análise do comportamento nas organizações envolve os fatores individuais expressados em face de determinado estímulo. Em meio à observação do comportamento dos indivíduos nas organizações, muitos autores já retrataram o sentimento de poder que o indivíduo tem nas suas relações organizacionais. As hierarquias, cargo ocupado e tempo de empresa criam nos membros da organização um sentimento de poder perceptível no comportamento do indivíduo nas relações organizacionais.

No mundo moderno, uma fonte de poder nas organizações é o conhecimento (TOFFLER, 1990). Para Alcará et al. (2009), o sentimento de que o conhecimento é poder, destaca-se dentre os fatores motivacionais que influenciam o compartilhamento de informações. Assim, quando a informação representa a principal moeda para quem a detém, não se pode esperar que esta informação seja facilmente compartilhada (DAVENPORT, 1998). Com isso, o indivíduo cria uma sensação de propriedade psicológica deste conhecimento (VAN DYNE, PIERCE, 2004), e então a informação e o conhecimento passam a ser vistos como uma forma de propriedade que, ao ser entregue, expõe o sujeito a ameaças de perda de status dentro da organização (YANG, MAXWELL, 2011).

Este sentimento de posse pode gerar, ao mesmo tempo, a concorrência e a colaboração e impedir o comportamento da partilha de informação (YANG, MAXWELL, 2011). Para Alcará et al., (2009), esse sentimento de posse, muitas vezes, torna-se um obstáculo no compartilhamento da informação. Se um indivíduo pensa que seu conhecimento valioso o torna importante na organização, pode relutar em compartilhá-lo para manter sua posição de "poder" (CHONG, BESHARATI, 2014). O indivíduo precisa compreender que compartilhar não acarreta ceder posse do conhecimento, mas sim usufruir dele em parceria com outros (ALCARÁ et al., 2009).

Desta forma, o artigo objetivou analisar a relação da influência da propriedade psicológica que o indivíduo possui sobre o conhecimento a respeito de determinado assunto ou modo de executar uma tarefa na sua intenção de compartilhar esse conhecimento criado ou adquirido com demais membros da organização e no sentimento de poder que possui dentro da organização, através da percepção de jovens empreendedores da região da Serra Gaúcha, no nordeste do estado do Rio Grande do Sul.

\section{Referencial teórico}

Ao considerar o objetivo do estudo, o referencial teórico envolve as discussões sobre poder, bem como as suas bases nas organizações. A partir das definições de poder, discutiu-se a propriedade psicológica que o indivíduo tem em relação ao conhecimento e a intenção de compartilhar conhecimento nas organizações.

\section{PODER NAS ORGANIZAÇÕES}

\begin{abstract}
"Ao fazemos ou desejarmos o bem exercemos o nosso poder sobre aqueles que de um modo ou de outro, estão já na nossa dependência (quer dizer que se habituaram a pensar em nós como nas suas causas); queremos aumentar o seu poder porque assim aumentamos o nosso, ou queremos mostrar-lhes a vantagem que há em estar em nosso poder; ficarão mais satisfeitos com a sua situação e mais hostis aos inimigos do nosso poder, mais prontos a combatê-los. O fato de fazermos sacrifícios para fazer o bem ou o mal não altera em nada o valor definitivo dos nossos atos; mesmo se arriscarmos a nossa vida, como o mártir pela sua igreja, é um sacrifício que fazemos à nossa necessidade de poder, ou a fim de conservar o nosso sentimento de poder" (NIETZSCHE, 2001, p.13).
\end{abstract}

O sentimento de poder é pertencente à natureza do ser humano. A "Vontade do Poder" é retratada por Nietzsche nos valores e na moral de acordo com a natureza dos homens, diretamente ligado às forças e fraquezas, amor e crueldade, prazer e dor, as quais são diretamente relacionadas à sensação do poder dos homens. As relações de poder que permeiam a sociedade humana já eram retratadas por Maquiavel com enfoque na ciência política. Em 1513, Maquiavel discutia na sociedade política, o desejo pelo poder como algo que se coloca de modo insaciável em uma relação que requer precauções, como o temor ao desprezo e 
ao ódio. No plano político, os homens têm o desejo de dominar e governar, o que remete a uma relação de antagonismo e de complementaridade (MAQUIAVEL, 1961). O autor ainda considera que a complementaridade consolida-se na perspectiva onde o "poder" do governante é algo que emana da própria sociedade. Desta forma, os governantes não conseguem manterem-se no poder sem o apoio do povo.

Nesta perspectiva, Marx (1844) acredita na arte de governar como exercício do poder, conforme o modelo da economia. Marx percebia o poder como um modo de opressão usado pela burguesia a fim de explorar e obter lucros sobre o proletariado (operários e camponeses). A relação de poder, segundo Marx, relaciona as classes sociais com favorecimento à classe burguesa, e assim o proletariado só pode viver se encontrar trabalho, este controlado pela burguesia para acumular capital. Ou seja, o trabalho passa a ser um mecanismo de dominação na sociedade capitalista.

Em diferente perspectiva, Foucault (1978) acredita que o poder da dominação capitalista retratada por Marx (1844) não conseguiria manter-se baseado exclusivamente na repressão. Foucault (1978) tende a ver o poder de forma mais positiva, favorável à eficácia produtiva e a uma riqueza de estratégias. O poder atua na sociedade como combustível propulsor do progresso e do avanço científico. Entretanto, os jogos de poder supõem os conflitos complexos compreendidos por meio a relações com interesses específicos e, neste ponto, encontra-se o saber. Saber é o processo no qual o sujeito do conhecimento sofre modificações durante o trabalho que realiza na atividade de conhecer. Ou seja, o saber é sutil, em constante mudança e influenciado pelo ganho de conhecimentos. Foucault (1978) foi um dos primeiros intelectuais que relacionou de maneira explícita o saber e o poder. Com isso, tratou como a diferença dos saberes modifica as relações sociais. Segundo o filósofo, cada época tem um discurso/ação que muda o sujeito e o objeto, pois é este individuo quem trama o saber.

Em uma perspectiva multidimensional, French e Raven (1959) enfatizam que o poder pode ser exercido a partir de cinco formas distintas: poder coercitivo, poder de recompensa, poder legítimo, poder de referência e poder especialista. Também segundo French e Raven (1959), as diferentes formas de poder influenciam as atitudes e comportamentos das pessoas que exercem o poder sobre as demais. Nesler et al. (1999) discutem as ideias de French e Raven (1959) e desenvolvem o conceito de poder global, que engloba questões relacionadas aos cinco poderes descritos por French e Raven (1959). Nesler et al. (1999) chegam a conclusão que o poder pode ser dividido em três dimensões: poder global, poder de referência e poder legítimo. Estas dimensões podem ser visualizadas No Quadro 1.

Quadro 1. Dimensões de poder segundo Nasler et al. (1999)

\begin{tabular}{|c|l|}
\hline PODER & \multicolumn{1}{c|}{ DEFINIÇÃO } \\
\hline $\begin{array}{c}\text { Poder Global } \\
\text { (Global Power) }\end{array}$ & $\begin{array}{l}\text { Definido a partir dos conceitos de poder social de Weber (1947) e Emerson (1962), ao argumentarem } \\
\text { que o poder social envolve a resistência do alvo. Schur (1969) sugere que o poder se refere à } \\
\text { habilidade que uma fonte de poder tem sobre um alvo. Ao englobar o controle da fonte de poder e a } \\
\text { resistência do alvo, Nesler et al, (1999) montam a definição de poder global relacionado à habilidade } \\
\text { de influência de um gestor, em uma perspectiva negativa da resistência e controle e apresentam um } \\
\text { contraponto do poder social. }\end{array}$ \\
\hline $\begin{array}{c}\text { Poder } \\
\text { Legítimo } \\
\text { (Legitimate } \\
\text { Power) }\end{array}$ & $\begin{array}{l}\text { Habilidade de administrar sentimentos de obrigação ou de responsabilidade (HINKIN; } \\
\text { SCHRIESHEIM, 1989). O poder legítimo está relacionado ao sentimento de obrigação e com } \\
\text { crenças que o sujeito aceita e respeita (MARTINS; GUIMARÂES, 2007), e a aptidão de uma } \\
\text { pessoa influenciar o comportamento dos demais devido a sua posição dentro da empresa, } \\
\text { muitas vezes mencionada como “autoridade formal" (LUNENBURG, 2013). O poder legítimo } \\
\text { ocorre quando o alvo percebe que um agente de influência tem o direito de afetar-lhe, devendo, } \\
\text { desta forma, cumprir seu pedido. Isto ocorre quando o agente possui um papel socialmente } \\
\text { reconhecido ou posição que a outra pessoa (alvo) reconhece, como por exemplo a relação entre } \\
\text { chefe e funcionário (SIMPSON et al., 2015). }\end{array}$ \\
\hline
\end{tabular}




\begin{tabular}{|c|l|}
\hline $\begin{array}{c}\text { Poder de } \\
\text { Referência } \\
\text { (Referent } \\
\text { Power) }\end{array}$ & $\begin{array}{l}\text { Habilidade de gerir sentimentos de aceitação ou aprovação pessoal (HINKIN; SCHRIESHEIM, } \\
\text { 1989). Diferentemente do poder legítimo, o poder de referência é a habilidade de uma pessoa } \\
\text { influenciar o comportamento dos outros, porque eles gostam, admiram e respeitam o indivíduo } \\
\text { influência e ocorre devido à admiração que o alvo possui pelo agente (SIMPSON et al., 2015). } \\
\text { O poder de referência nasce a partir da admiração do outro e do desejo de ser como essa pessoa } \\
\text { (LUNENBURG, 2013). }\end{array}$ \\
\hline
\end{tabular}

Fonte: Adaptado de Nasler et al. (1999).

Com base nas contribuições de Nasler et al. (1999) entende-se então que o poder no ambiente organizacional pode assumir formas distintas, seja pelo poder oriundo de relações formais da relação chefia/ empregado, ou pelas relações informais, que geram referencias de liderança e comportamento e desta forma acabam por influenciar seus colegas de trabalho. Mais além, pode-se refletir que os detentores das 3 formas de poder (global, legítimo ou de referência) acabam por desempenhar papeis chaves no dia-a-dia organizacional, e por consequência acabam sendo intermediadores ou fontes (formais ou informais) de conhecimento nas organizações. Neste aspecto, o conhecimento estratégico pode ser considerado uma fonte de poder, uma vez que ser o deter o conhecimento do negócio pode colocar o indivíduo neste papel chave. Assim, o poder pode criar no individuo o sentimento da propriedade psicológica no conhecimento organizacional.

\section{Propriedade psicológica do conhecimento}

"Conhecimento é a fonte suprema de poder na economia mundial, o que ajuda a explicar por que a batalha pelo conhecimento do controle e os meios de comunicação está se aquecendo em todo o mundo" (TOFFLER, 1990, p.10). O conceito de Toffler (1990) defende o conhecimento como uma fonte de poder nas organizações e em uma economia moderna. O controle deste conhecimento e dos meios de comunicação podem ser considerados fontes de poder. Por isso, o conhecimento torna-se algo a ser protegido pelo indivíduo e, com isso, as pessoas desenvolvem sentimentos de posse idênticos ao criado por diversos objetos materiais. Este sentimento denomina-se propriedade psicológica (PIERCE, KOSTOVA E DIRKS, 2003). Segundo Van Dyne e Pierce (2004), a propriedade psicológica é um fenômeno psicológico experimentado, no qual um empregado desenvolve um sentimento de posse. Este sentimento de posse pode se manifestar em diferentes alvos e varia em cada indivíduo e situação (VAN DYNE E PIERCE, 2004). Além disso, pode ser dirigido para a organização como um todo ou para aspectos específicos, como o grupo, ferramentas de trabalho ou até mesmo a própria atividade (VAN DYNE E PIERCE, 2004). Em seu estudo, os autores enfatizam a posse como o único núcleo de propriedade psicológica para a organização e sugerem que esta natureza possessiva se diferencia das demais atitudes relacionadas ao trabalho.

O entendimento da propriedade psicológica possibilita à organização uma compreensão de atitudes e comportamentos dos funcionários com o empenho e a satisfação. Avey et al. (2009) analisaram a propriedade psicológica e, da mesma forma que Van Dyne e Pierce (2004), consideraram a propriedade psicológica como um recurso positivo, capaz de causar impacto no desempenho humano nas organizações. O sentimento de posse gera nas pessoas uma predisposição a investirem tempo e energia quando sentem que um conjunto de ideias é verdadeiramente delas, além de estimular as pessoas a estarem abertas a sugestões de mudança (BAER; BROWN, 2012).

A propriedade psicológica apresenta uma série de resultados positivos, porém, Van Dyne e Pierce (2004) alertam para a importância de reconhecer os efeitos potencialmente negativos em casos extremos de propriedade psicológica. Pierce, Kostova e Dirks (2003) apontam que o estado psicológico de propriedade pode apresentar um lado escuro. Um elevado grau de propriedade pode desencadear o lado negativo da possessividade. Os indivíduos podem não estar dispostos a compartilhar o alvo da propriedade com os demais ou podem sentir que precisam manter o controle exclusivo deste alvo e esta atitude, por sua vez, provavelmente impedirá a cooperação (PIERCE, KOSTOVA E DIRKS, 2003).

Desde o momento em que o conhecimento é adquirido, controlado ou criado pelas pessoas, elas naturalmente reconhecem que o conhecimento é a sua 
propriedade psicológica pessoal e, consequentemente, irão retê-lo. Desta forma, pode-se considerar que a propriedade psicológica do conhecimento possui uma relação positiva com a ocultação do conhecimento (PENG, 2013). Entretanto, o efeito desta ocultação de conhecimento individual pode gerar uma série de consequências as organizações. Grande parte do conhecimento tácito da organização se perde uma vez que a empresa se detém apenas a manter o conhecimento formalizado ou explicito.

Entretanto, as empresas não podem gerenciar o conhecimento tácito de seus funcionários, ou ter a ilusão que o conhecimento organizacional está apenas nos documentos explícitos. Os relacionamentos, o know-how, a cultura organizacional de natureza tácita só será compartilhada a medida que as pessoas pertencentes a organização têm a intenção de compartilhar conhecimento com os demais. Por isso, pode-se então questionar se o sentimento da propriedade psicológica do conhecimento pode ter influencia na intenção dos indivíduos em compartilhar conhecimento nas organizações, emergindo assim o objetivo desta pesquisa.

\section{Intenção de compartilhar de conhecimento}

No campo da Teoria da Ação Racional (AJZEN; FISHBEIN, 1977), assume-se que a intenção comportamental trata da força de uma pessoa realizar um determinado comportamento. A intenção comportamental relaciona o comportamento às normas subjetivas e estas, por sua vez, são vistas como a influência das pessoas no ambiente social, a qual também terá influência em executar o comportamento em questão. A teoria da Ação Racional pode ser relacionada ao campo do conhecimento, na intenção do indivíduo em compartilhar conhecimento. Bock e Kim (2002) salientam que o comportamento de compartilhar conhecimento é motivado e executado principalmente em nível individual e trata o compartilhamento de conhecimento como uma ação comportamental relacionada diretamente ao indivíduo que detém o conhecimento. Neste sentido Gibbert e Krause (2002) argumentam que o compartilhamento do conhecimento se encontra na vontade dos indivíduos em compartilharem os conhecimentos criados ou adquiridos.

Nonaka e Takeuchi (1997) tratam a intenção de compartilhar como uma condição capacitadora para criação do conhecimento. As condições capacitadoras dão enfoque ao contexto no qual o conhecimento é criado. Segundos os autores, é necessário que o contexto seja apropriado para que as atividades em grupo resultem em criação e acúmulo de conhecimento em nível individual. Neste sentido, a primeira condição capacitadora retratada é a intenção. A intenção dos indivíduos em adquirir, criar, acumular e explorar o conhecimento é a primeira condição para que novos conhecimentos sejam criados.

De acordo com Tomaél (2012), o termo compartilhamento possui muitos significados, porém, atualmente, os empregos mais utilizados estão vinculados à tecnologia da informação e às relações pessoais. Nos dois casos, os propósitos são os mesmos, compartilhar, utilizar, conhecer, usufruir ou participar de ações presentes em espaços multifacetados. Além de aprimorar a eficiência e diminuir significativamente o custo de muitos produtos e serviços, o compartilhamento melhora a capacidade das empresas e contribui para o aprendizado organizacional (TOMAÉL, 2012).

Bock et al. (2005) salientam que os indivíduos consideram três níveis de forças motivadoras para o compartilhamento de conhecimento: o benefício individual, relacionado ao interesse próprio e o ganho pessoal que o conhecimento traz para o indivíduo; o benefício do grupo, relacionado a reciprocidade. Segundo os autores, esse benefício acontece quando a atitude de compartilhar conhecimento é guiada pelo relacionamento com os demais, e compartilhamento gera a sensação de recompensa por parte do grupo; e, por último, os indivíduos consideram o benefício gerado para a organização pelo compartilhamento do conhecimento. D'Arrigo et al. (2015) argumentam que a intenção de compartilhar conhecimento é a motivação individual que o membro da organização tem em relação ao conhecimento. A motivação para compartilhar conhecimento está intimamente relacionada ao valor percebido pelo individuo em relação a este conhecimento. Ou seja, quando o indivíduo percebe o valor deste conhecimento na organização e que o compartilhamento deste conhecimento pode perder este valor. Assim, é possível considerar que o comportamento de compartilhar conhecimento está relacionado ao sentimento e ao valor que o conhecimento tem para o indivíduo, e o compartilhamento pode beneficiar o grupo ou a organização. 


\section{Método}

Para avaliar a influência da propriedade psicológica que o indivíduo possui sobre o conhecimento, perante o poder do indivíduo na organização e a intenção de compartilhar este conhecimento com os demais, realizou-se uma pesquisa exploratória e utilizou-se uma abordagem quantitativa. O campo deste estudo foi elencado por tratar-se de jovens empresários que possuem empresas no ramo do comércio nas cidades de Bento Gonçalves, Caxias do Sul, Farroupilha, Flores da Cunha e Antônio Prado, municípios localizados na Serra Gaúcha, no Estado do Rio Grande do Sul - Brasil. Os jovens fazem parte de uma associação que visa o desenvolvimento do comércio de maneira organizada, através da qualificação das empresas e dos gestores, além da união de lojistas em prol dos interesses da classe. No total foram respondidos 89 questionários no período de novembro a dezembro de 2014.

A intenção de entender a relação do poder, conhecimento e o sentimento de propriedade deste conhecimento em empreendedores jovens, dá-se pelo fato dos jovens empreendedores demonstrarem características relacionadas a atitudes e comportamentos flexíveis. Empreendedores jovens são abertos a novas ideias, o que estimula o fluxo de conhecimento das empresas (HENDERSON, ROBERTSON, 2000).

A coleta de dados com os jovens empreendedores foi realizada através de um instrumento com questões fechadas de escolhas simples, do tipo escala de Likert de cinco pontos, que variaram de "discordo totalmente" a "concordo totalmente". Os itens foram apresentados em formato de afirmação, como por exemplo: "Vou tentar compartilhar a experiência de minha educação com outros membros da organização de uma forma mais eficaz", e "Na figura de gestor, eu posso influenciar o comprometimento de meus colaboradores". Ainda, inicialmente, houve uma abordagem explicativa referente ao objetivo da pesquisa, com orientações aos respondentes e uma nota que assegurava confidencialidade das informações concedidas.

Para construção do questionário foram utilizados os instrumentos de pesquisa de Bock et al., (2005) e D’Arrigo et al., (2015) para as questões relacionadas a intenção de compartilhar conhecimento; Van Dyne e Pierce (2004) e Peng (2013), para as questões relacionadas a propriedade psicológica do conhecimento e Nesler et al. (1999) e Hinkin e Schriesheim (1989) para as questões relacionadas ao poder nas organizações. Inicialmente, o questionário foi aplicado a uma amostra piloto de 12 respondentes e contemplou os construtos conforme o Quadro2. Quanto ao tamanho da amostra, levou-se em consideração a afirmação de Hair Jr. et al., (2005), o qual apresenta que, para cada variável do questionário deve-se ter pelo menos 5 respondentes. O questionário está composto por 12 variáveis, o que caracteriza uma média de 7,4 respondentes por variável e que revela que a amostra está adequada.

Quadro 2 . Construtos e questões do instrumento utilizado na pesquisa

\begin{tabular}{|c|c|c|}
\hline CONSTRUTOS & INDICADORES & SIGLAS \\
\hline \multirow{5}{*}{$\begin{array}{l}\text { Intenção de } \\
\text { compartilhar } \\
\text { conhecimento }^{1}\end{array}$} & $\begin{array}{l}\text { Tento compartilhar a experiência de minha educação com outros } \\
\text { membros da organização de uma forma mais eficaz. }\end{array}$ & ICC-TACITO ${ }^{1}$ \\
\hline & $\begin{array}{l}\text { Tenho a intenção de partilhar a minha experiência ou know-how de } \\
\text { trabalho com outros membros da organização com mais frequência } \\
\text { no futuro. }\end{array}$ & ICC-TACITO ${ }^{2}$ \\
\hline & $\begin{array}{l}\text { Eu sempre vou fornecer os meus manuais, metodologias entre } \\
\text { outros documentos escritos para os membros da minha organização. }\end{array}$ & $\begin{array}{l}\text { I C C C - } \\
\text { EXPLICITO }^{1}\end{array}$ \\
\hline & $\begin{array}{l}\text { Vou compartilhar meus relatórios de trabalho e documentos oficiais } \\
\text { com membros da minha organização com mais frequência no } \\
\text { futuro. }\end{array}$ & $\begin{array}{l}\text { I C C }{ }^{-}- \\
\text {EXPLICITO }^{2}\end{array}$ \\
\hline & $\begin{array}{l}\text { Eu sempre vou compartilhar meu know-how e minha rede de } \\
\text { contatos, a pedido de outros membros da organização. }\end{array}$ & $\begin{array}{l}\text { I } \mathrm{C} \quad \mathrm{C} \\
\text { EXPLICITO }^{3}\end{array}$ \\
\hline
\end{tabular}




\begin{tabular}{|c|c|c|}
\hline \multirow{2}{*}{$\begin{array}{l}\text { Propriedade } \\
\text { Psicológica do } \\
\text { Conhecimento }^{2}\end{array}$} & $\begin{array}{l}\text { Eu sinto que os conhecimentos criados na empresa são parte de } \\
\text { mim. }\end{array}$ & $\begin{array}{l}\text { P } \quad \mathrm{R} \quad \mathrm{O} \\
\text { PSICOL. }\end{array}$ \\
\hline & $\begin{array}{l}\text { Eu me sinto em um grau elevado de propriedade do conhecimento } \\
\text { presente na minha empresa. }\end{array}$ & $\begin{array}{l}\mathrm{P} \quad \mathrm{R} \quad \mathrm{O} \mathrm{P} \\
\text { PSICOL. }^{2}\end{array}$ \\
\hline \multirow{5}{*}{$\begin{array}{l}\text { Poder (Global, } \\
\text { Legítimo e de } \\
\text { Referência) }^{3}\end{array}$} & $\begin{array}{l}\text { Na figura de gestor, eu posso influenciar meus colaboradores a } \\
\text { trabalhar duro. }\end{array}$ & PODER-PG \\
\hline & $\begin{array}{l}\mathrm{Na} \text { figura de gestor, eu posso influenciar os projetos dos meus } \\
\text { colaboradores. }\end{array}$ & PODER-PG \\
\hline & $\begin{array}{l}\text { Na figura de gestor, eu posso influenciar no comprometimento de } \\
\text { meus colaboradores. }\end{array}$ & PODER-PL $^{1}$ \\
\hline & $\begin{array}{l}\mathrm{Na} \text { figura de gestor, eu posso passar a sensação que meus } \\
\text { funcionários têm responsabilidades a seguir. }\end{array}$ & PODER-PL $^{2}$ \\
\hline & $\begin{array}{l}\text { Na figura de gestor, eu posso fazer meus funcionários se sentirem } \\
\text { valorizados e importantes. }\end{array}$ & PODER-PR \\
\hline
\end{tabular}

1. $\quad$ Bock et al. (2005); D’Arrigo et al. (2015)

2. Van Dyne and Pierce (2004) e Peng (2013)

3. Nesler et al. (1999) e Hinkin and Schriesheim (1989)

Fonte: Elaborado pelos autores

Para análise dos dados foram utilizadas técnicas estatísticas de análise descritiva e inferenciais. Os dados foram analisados com o auxílio do software IBM SPSS Statistics versão 21, Google Docs e planilha eletrônica.

\section{Caracterização da Amostra}

Com o propósito de buscar a percepção de empreendedores jovens, um critério de seleção foi a faixa etária (idade máxima de 35 anos). A maior parte dos respondentes (40,4\% ou 36 respondentes) encontra-se na faixa etária dos 31 aos 35 anos. A faixa de idade dos 26 aos 30 anos apresentou 38,2\% (34 respondentes) das respostas. Apenas 3,4\% (3 respondentes) dos respondentes afirmam ter menos de 20 anos de idade.

Todos os respondentes fazem parte de uma associação de empreendedores jovens, do ramo do comércio, de 5 diferentes cidades no Rio Grande do Sul. Cada cidade possui uma diretoria específica, com quantidade de representantes diferentes. A Tabela 1 mostra a composição das 5 diretorias questionadas. É importante ressaltar que todos os diretores jovens, das 5 cidades participantes desta associação responderam ao questionário.

Tabela 1. Frequência dos respondentes por diretoria

\begin{tabular}{c|c|c}
\hline Diretoria & Respondentes & Percentual \\
\hline Diretoria 1 & 17 & $19 \%$ \\
\hline Diretoria 2 & 24 & $27 \%$ \\
\hline Diretoria 3 & 7 & $8 \%$ \\
\hline Diretoria 4 & 13 & $14,5 \%$ \\
\hline Diretoria 5 & 28 & $31,5 \%$ \\
\hline Total & 89 & $100 \%$ \\
\hline
\end{tabular}

Fonte: Elaborado pelos autores 


\section{Resultados}

Com o propósito de identificar se os dados são normais, realizou-se o teste Kolmogorov-Smirnov de cada variável questionada. O teste mostra a distribuição de probabilidade dos dados, já que variáveis com distribuição normal são simétricas em torno da média e também da moda e da mediana (GIACOMELLO, 2009). O teste de Kolmogorov-Smirnov demonstrou que os dados apresentam simetria positiva (todos os indicadores apresentaram significância $=0,00)$, o que indica a normalidade dos dados obtidos. Os valores relativos ao teste, para cada variável podem ser visualizados na Tabela 2 (Comunalidades).

Após o teste de Kolmogorov-Smirnov ter sido executado, executou-se a análise fatorial exploratória. Outra forma para identificar se o modelo de análise fatorial está adequadamente ajustado aos dados, é testando a sua consistência geral, através da medida de adequação da amostra de Kaiser-Mayer-Olkin (KMO) (HAIR JR. ET AL., 2005). Quanto mais próximo de 1 , melhor o resultado, ou seja, mais adequada é a amostra à aplicação da análise fatorial. $\mathrm{Na}$ análise, o valor de KMO dos fatores foi de 0,612 , então, as amostras mostraram-se adequadas para a aplicação de análise fatorial $(\mathrm{KMO}>0,5)$.

Assim, procedeu-se a análise fatorial, que visa identificar os construtos ou dimensões básicas relacionadas aos dados e para reduzir o número de dimensões de análise (KUMAR, AAKER, DAY, 2002). Primeiramente, analisou-se a comunalidade dos indicadores. $\mathrm{Na}$ análise das comunalidades, Hair Jr. et al. (2005) indicam que sejam excluídas variáveis que apresentem o índice de comunalidade inferior a 0,5 , e, por isso, a variável TÁCITO1 $(0,400)$ foi retirada da análise. Após a exclusão da variável TÁCITO1, a análise fatorial foi executada novamente. $\mathrm{Na}$ segunda rodada da análise fatorial, foi adotado o critério de carga fatorial mínima de 0,5 em cada um dos fatores, já que se trata de uma análise exploratória. Esses dados da segunda rodada também podem ser visualizados na Tabela 2 .
Tabela 2. Comunalidades

\begin{tabular}{c|c|c|c}
\hline Variáveis & Inicial & $\begin{array}{c}\text { Extração } \\
\mathbf{1}\end{array}$ & $\begin{array}{c}\text { Extração } \\
\mathbf{2}\end{array}$ \\
\hline EXPLÍCITO 1 & 1,000 &, 684 & 0,694 \\
\hline EXPLÍCITO 2 & 1,000 &, 630 & 0,695 \\
\hline EXPLÍCITO 3 & 1,000 &, 642 & 0,654 \\
\hline TACITO1 & 1,000 &, 400 & - \\
\hline TACITO2 & 1,000 &, 768 & 0,771 \\
\hline PPC1 & 1,000 &, 770 & 0,774 \\
\hline PPC2 & 1,000 &, 726 & 0,726 \\
\hline PG1 & 1,000 &, 637 & 0,639 \\
\hline PG2 & 1,000 &, 595 & 0,606 \\
\hline PL1 & 1,000 &, 583 & 0,586 \\
\hline PL2 & 1,000 &, 739 & 0,738 \\
\hline PR & 1,000 &, 640 & 0,660 \\
\hline
\end{tabular}

Fonte: elaborada pelos autores

Com as comunidades alinhadas prosseguiu-se com a análise fatorial. Ela resultou em 4 fatores que explicam $68,56 \%$ dos dados. Com o intuito de facilitar a interpretação dos fatores, foi empregado o método de componentes principais com rotação ortogonal de fatores, a rotação Varimax, minimizando o número de variáveis com cargas altas sobre um fator e reforçando a interpretação de Malhotra (2006), Kumar, Aaker e Day (2002), por meio da maximização das variâncias das cargas dos fatores JOHNSON, WICHERN, 2002). Esse fato evidenciou que a matriz de correlações é adequada à técnica de análise escolhida. 
Tabela 3 . Fatores identificados

\begin{tabular}{|c|c|c|c|c|c|}
\hline Fator & Fator Renomeado & Indicador & Carga Fatorial & KMO & Alpha \\
\hline \multirow{5}{*}{1} & \multirow{5}{*}{ Poder } & PG1 & 0,558 & \multirow{5}{*}{0,730} & \multirow{5}{*}{0,742} \\
\hline & & PG2 & 0,705 & & \\
\hline & & PL1 & 0,737 & & \\
\hline & & PL2 & 0,830 & & \\
\hline & & PR & 0,639 & & \\
\hline \multirow{3}{*}{2} & \multirow{3}{*}{$\begin{array}{l}\text { Intenção de compartilhar } \\
\text { conhecimento explícito }\end{array}$} & EXPLIC1 & 0,810 & \multirow{3}{*}{0,643} & \multirow{3}{*}{0,681} \\
\hline & & EXPLIC2 & 0,818 & & \\
\hline & & EXPLIC3 & 0,682 & & \\
\hline \multirow{2}{*}{3} & \multirow{2}{*}{ Propriedade Psicológica do Conhecimento } & PPC1 & 0,879 & \multirow{2}{*}{0,599} & \multirow{2}{*}{0,700} \\
\hline & & PPC2 & 0,839 & & \\
\hline 4 & Intenção de compartilhar conhecimento tácito & TACITO 2 & 0,871 & - & - \\
\hline
\end{tabular}

Fonte: elaborada pelos autores

Definidos e renomeados os fatores, realizou-se o KMO e o Alpha de Cronbach de cada novo fator, conforme a Tabela 5, com a intenção de medir a confiabilidade e a consistência interna dos fatores gerados (KLINE, 2005). Segundo Hair Jr. et al. (2005), o ideal é que o Alpha de Cronbach tenha resultado acima de 0,7. Entretanto, em pesquisas exploratórias, este valor pode diminuir para $0,6 . \mathrm{Na}$ Tabela 5 , também é possível perceber que o Alpha de Cronbach de três fatores ficaram (1, 2 e 3 ) ficaram acima ou perto do valor ideal. Além disso, o último fator gerado, por sua vez, possui apenas uma variável que apresenta carga fatorial significativa. Assim, o quarto fator ficou constituído apenas pelo conhecimento tácito 2 .

O fator 1 englobou as variáveis referentes ao poder do gestor influenciar os projetos, comprometimento, responsabilidade e sentimento de valorização dos colaboradores. Por englobar os três tipos de poder, o fator foi renomeado como "Poder". Este resultado indica que para os respondentes em questão, o poder é considerado um fator único, o que reforça os estudos de Nedler et al. (1999) ao afirmarem que as três dimensões constituem a visão do poder. Por terem sido agrupadas em único fator, exclusivamente com variáveis relacionadas ao poder (mesmo que considerando o poder de forma unidimensional), fica claro que as variáveis de pôr se distinguem das variáveis relacionadas a propriedade psicológica e a intenção de compartilhar conhecimento. O mesmo acontece com o fator 2, o qual envolve as variáveis referentes ao compartilhamento de materiais de trabalho, relatórios e documentos. O fator 2 também foi unicamente composto de variáveis referentes ao conhecimento explícito, e por isso, recebeu o nome de "Intenção de Compartilhar Conhecimento Explícito”. O fator 3 englobou unicamente variáveis referentes a sentimento de propriedade de conhecimento dos gestores e, por isso, foi renomeado como "Propriedade Psicológica Do Conhecimento". Isto indica que as variáveis referentes a este fator não se associaram aos demais construtos abordados. O último fator englobou apenas a variável relacionada ao conhecimento tácito e a intenção de compartilhar conhecimento no futuro.

\section{Regressão}

A literatura identificou que o sentimento de que o conhecimento é poder, destaca-se dentre os fatores motivacionais que influenciam o compartilhamento de informações (ALCARÁ et al. 2009). Mas para entender o papel da propriedade psicológica do conhecimento em relação ao poder e intenção de compartilhar conhecimento, realizou-se regressão linear, pelo método retroceder, para analisar a multicolinearidade dos construtos em relação ao fator da Propriedade Psicológica do Conhecimento. Segundo Hair Jr. et al., (2005), a multicolinearidade é a extensão em que 
uma variável pode ser explicada pelas outras variáveis em análise. Neste caso, analisa-se a influência da propriedade Psicológica do Conhecimento em relação às variáveis independentes (intenção de compartilhar conhecimento tácito, intenção de compartilhar conhecimento explícito e poder).

Figura 1. Influência da propriedade psicológica do conhecimento sobre o poder e a intenção de compartilhar conhecimento

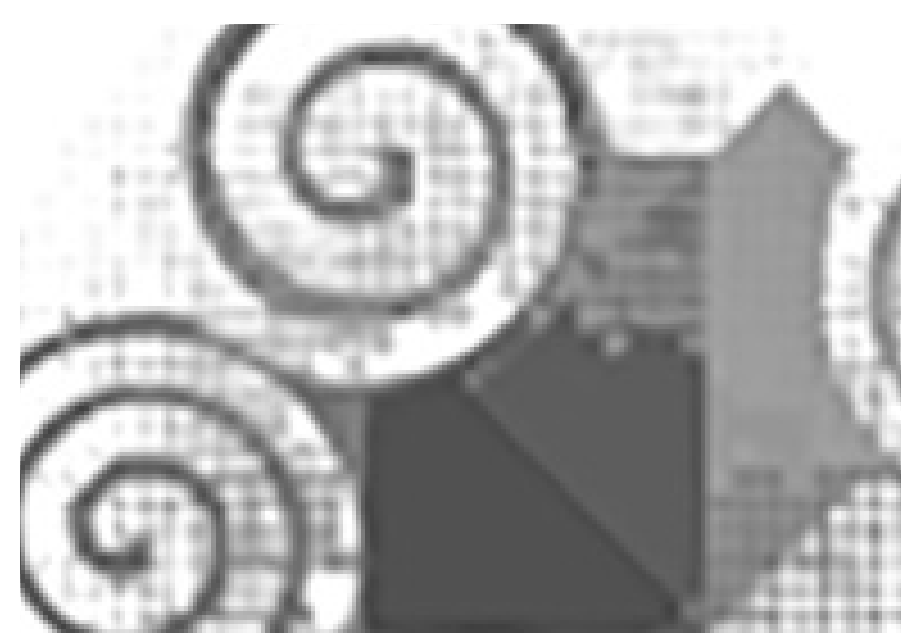

Fonte: Elaborada pelos autores

A Figura 1 é resultado da regressão linear. A relação entre Propriedade Psicológica do Conhecimento e o Poder apresentou os maiores coeficientes $(\mathrm{R}=$ 0,365). Ao analisar este resultado, podemos nos remeter as considerações de Van Dyne e Pierce (2004), que afirmam que a propriedade psicológica é um fenômeno psicológico experimentado, no qual um empregado desenvolve um sentimento de posse e então a informação e o conhecimento passam a ser vistos como uma forma de propriedade que, ao ser entregue, expõe o sujeito a ameaças de perda de status dentro da organização. Ou seja, a influência da propriedade psicológica do conhecimento é mais forte quando refere ao poder na organização.

Em relação a Intenção de compartilhar conhecimento, percebem-se maiores coeficientes relacionados ao compartilhamento do conhecimento explícito $(\mathrm{R}=$ $0,197)$ do que tácito $(\mathrm{R}=0,143)$. Neste ponto, percebeuse que na análise fatorial, o conhecimento tácito teve variáveis excluídas, remanescendo a variável da intenção de compartilhar conhecimento tácito no futuro. Os baixos valores da relação propriedade psicológica dos indivíduos e a intenção de compartilhar conhecimento tácito podem fornecer indícios que os gestores têm a intenção de compartilhar o conhecimento explícito (BOCK et al. 2005, D'ARRIGO et al. 2015).

\section{Discussão}

Por muito tempo as relações de poder nas organizações vêm sendo alvo de discussões teóricas. Nietzsche, Marx e Foucault discutem o poder na construção e interação dos seres humanos no convívio em sociedade e em organizações. Em uma visão pragmática do sentimento do poder nas organizações, o estudo teve como objetivos entender o papel da propriedade psicológica que os indivíduos sentem sobre o conhecimento e a influência deste sentimento na intenção de compartilhar conhecimento e na percepção de poder do individuo dentro das organizações.

Os resultados desta pesquisa trazem contribuições para a compreensão de como o lado comportamental dos indivíduos influencia o fluxo de conhecimento nas organizações. Ao mesmo em que tempo que já se sabe que o compartilhamento de conhecimento favorece a organização por dar valor aos recursos intangíveis das organizações (NONAKA; TAKEUCHI, 1997), percebeu-se que a intenção de compartilhar o conhecimento com os demais membros é relacionada ao sentimento de posse sobre este conhecimento. Compartilhar conhecimento com os demais membros da organização pode ser visto pelos indivíduos como perda da vantagem do indivíduo na organização, e, com isso, a perda do poder.

A análise fatorial mostrou que as variáveis de poder global, de referência e legítimo, agruparam-se entre si, criando um único fator. Tal indicador reforça os estudos de Nedler et al. (1999) ao afirmarem que as três dimensões constituem a visão do poder.

Os resultados do fator poder, quando relacionados a propriedade psicológica do conhecimento dos indivíduos, apresentaram coeficientes mais altos do que a intenção de compartilhar conhecimento, tanto tácito com explícito. Tal resultado indica que o sentimento de propriedade que os gestores têm sobre o conhecimento está relacionado ao sentimento de poder que este gestor tem na organização. Pierce, Kostova e Dirks (2003) apontam que o estado psicológico de propriedade pode apresentar um lado escuro. Um elevado grau de propriedade pode estimular o lado negativo da possessividade. Desde 
o momento em que o conhecimento é adquirido, controlado ou criado pelas pessoas, elas naturalmente caracterizam o conhecimento como sua propriedade psicológica pessoal e, consequentemente, irão retê-lo. Desse modo, pode-se considerar que a propriedade psicológica do conhecimento possui uma relação positiva com a ocultação do conhecimento (PENG, 2013).

Com relação a propriedade psicológica do conhecimento dos indivíduos e a intenção de compartilhar conhecimento, pode-se destacar que os coeficientes foram mais altos quando relacionados ao conhecimento explícito. Neste ponto, percebeuse que, na análise fatorial, o conhecimento tácito teve variáveis excluídas, remanescendo a variável da intenção de compartilhar conhecimento tácito no futuro.

Osbaixosvalores darelaçãopropriedadepsicológicados indivíduos e a intenção de compartilhar conhecimento tácito podem fornecer indícios que os gestores têm a intenção de compartilhar o conhecimento explícito (BOCK et al. 2005, D’ARRIGO et al. 2015).

\section{Considerações finais}

O objetivo deste trabalho foi identificar a influência da propriedade psicológica na intenção de compartilhar este conhecimento com os demais membros e o sentimento de poder do indivíduo na organização. Para identificar tal influência, a pesquisa de abordagem quantitativa descritiva, ouviu 89 diretores de uma associação de jovens empreendedores da região da Serra Gaúcha, no Rio Grande do Sul. A análise dos dados indica que a propriedade psicológica do conhecimento afeta a intenção de compartilhar conhecimento tácito e explícito com os demais membros da organização.

A principal contribuição deste trabalho refere-se a constatação de que a propriedade psicológica do conhecimento afeta a intenção de compartilhar conhecimento tácito e explícito com os demais membros da organização. Compartilhar conhecimento com os demais membros da organização pode ser visto pelos indivíduos como perda da vantagem do indivíduo para com a organização, e, com isso, a perda do poder.

A pesquisa buscou compreender a percepção individual dos empreendedores e, por isso, a coleta de dados ocorreu diretamente a estes empreendedores.
Entretanto, responder questões relacionadas à própria atuação na organização pode ser considerada uma limitação para este estudo. A autoanálise permite a coleta de dados em uma perspectiva, o que pode deixar de apresentar indicadores diferentes quando observados em multiperspectivas. Sugere-se, para estudos futuros, a expansão do ambiente de pesquisa, questionando também colaboradores ou stakeholders. Asim poderá ser possível realizar a análise em diferentes perspectivas. Outro ponto a ser considerado em pesquisas futuras é o aprofundamento em estudos que relacionem a intenção de compartilhar conhecimento tácito com a propriedade psicológica dos indivíduos. Estudos qualitativos e em profundidade podem revelar indícios de como a intenção de compartilhar conhecimento tácito relaciona-se ao sentimento de posse e poder que este conhecimento tem nos gestores.

\section{Referencias}

AJZEN, Icek; FISHBEIN, Martin. Attitude-behavior relations: A theoretical analysis and review of empirical research. Psychological bulletin, v. 84, n. 5, p. 888, 1977.

ALCARÁ, Adriana Rosecler et al. compartilhamento da informação e do conhecimento. Perspectivas em ciência da informação, v. 14, n. 1, p. 170-191, 2009.

AVEY, James B. et al. Psychological ownership: Theoretical extensions, measurement and relation to work outcomes. Journal of Organizational Behavior, v. 30, n. 2, p. 173-191, 2009.

BAER, Markus; BROWN, Graham. Blind in one eye: How psychological ownership of ideas affects the types of suggestions people adopt. Organizational Behavior and Human Decision Processes, v. 118, n. 1, p. 60-71, 2012.

BOCK, Gee-Woo; KIM, Young-Gul. Breaking the myths of rewards: An exploratory study of attitudes about knowledge sharing. Pacis 2001 proceedings, p. 78, 2001.

BOCK, Gee-Woo et al. Behavioral intention formation in knowledge sharing: Examining the roles of extrinsic motivators, social-psychological forces, and organizational climate. MIS quarterly, p. 87111, 2005. 
CHONG, Chin Wei; BESHARATI, Jamshid.

Challenges of knowledge sharing in the petrochemical industry. Knowledge Management \& E-Learning: An International Journal (KM\&EL), v. 6, n. 2, p. 171-187, 2014.

D'ARRIGO, Fernanda Pauletto et al. The influence of knowledge sharing intention in the process of knowledge acquisition and exploitation: a study with young entrepreneurs. Business and Management Review, v. 5, n.1, p. 642-651.

DAVENPORT, Thomas H.; ECCLES, Robert G.; PRUSAK, Laurence. Information politics. The strategic management of intellectual capital, p. 101-119, 1998.

EMERSON, Richard M. Power-dependence relations. American sociological review, p. 31-41, 1962.

FRENCH, John RP; RAVEN, Bertram;

CARTWRIGHT, D. The bases of social power.

Classics of organization theory, p. 311-320, 1959.

FOUCAULT, Michel; VARELA, Julia. Microfísica del poder. 1978.

GIACOMELLO, Cíntia Paese. Relação entre inteligência estratégica e orientação para o mercado e seus impactos no desempenho das organizações. 2009. Tese de Doutorado. Porto Alegre:

Universidade Federal do Rio Grande do Sul.

GIBBERT, Michael; KRAUSE, Hartmut. Practice exchange in a best practice marketplace. Knowledge management case book: Siemens best practices, p. 89-105, 2002.

HAIR, Joseph F. et al. Análise multivariada de dados. Bookman, 2009.

HENDERSON, Roger; ROBERTSON, Martyn. Who wants to be an entrepreneur? Young adult attitudes to entrepreneurship as a career. Career Development International, v. 5, n. 6, p. 279-287, 2000.

HINKIN, Timothy R.; SCHRIESHEIM, Chester A. Development and application of new scales to measure the French and Raven (1959) bases of social power. Journal of Applied Psychology, v. 74, n. 4, p. $561,1989$.

JOHNSON, Richard Arnold; WICHERN, Dean W. Clustering, distance methods, and ordination.
Applied multivariate statistical analysis, v. 4, p. 726-99, 1998.

Kline, Rex B. Principles and practice of structural equation modeling (2nd ed.). New York: Guilford Press. 1999

KUMAR, Vinay; AAKER, David A.; DAY, George S. Essentials of marketing research. New York, NY: Wiley, 2002.

LUNENBURG, Fred C. Power and leadership: an influence process. International journal of management, business, and administration, $\mathrm{v}$. 15, n. 1, p. 1-9, 2012.

MALHOTRA, Naresh K. Questionnaire design and scale development. The handbook of marketing research: Uses, misuses, and future advances, p. 176-202, 2006.

MAQUIAVEL, Nicolau. Le prince. Paris, France. 1961

MARTINS, Maria do Carmo Fernandes; GUIMARÃES, Vanessa da Fonseca. Adaptação e validação da escala de bases de poder do supervisor (EBPS). Revista Psicologia, v. 7, n. 2, p. 54-77, 2007.

MARX, Karl. Economic and philosophical manuscripts. Moscow. 1844.

NESLER, Mitchell S. et al. The Development and Validation of a Scale Measuring Global Social Power Based on French and Raven's Power Taxonomy1. Journal of Applied Social Psychology, v. 29, n. 4, p. 750-769, 1999.

NIETZSCHE, Friedrich. A gaia ciência. trad. Paulo César de Souza. São Paulo: Companhia das Letras, 2001.

TAKEUCHI, Hirotaka; NONAKA, Ikujiro. Criação de conhecimento na empresa. Rio de Janeiro: Campus, 1997.

PENG, He. Why and when do people hide knowledge?. Journal of Knowledge Management, v. 17, n. 3, p. 398-415, 2013.

PIERCE, Jon L.; KOSTOVA, Tatiana; DIRKS, Kurt T. The state of psychological ownership: Integrating and extending a century of research. Review of general psychology, v. 7, n. 1, p. 84, 2003. 
SCHUR, Edwin Michael. Law and Society. A

Sociological View. 1969.

SIMPSON, Jeffry A. et al. Power and social influence in relationships. APA handbook of personality and social psychology: Interpersonal relations, p. 393-420, 2015.

TOMAÉL, Maria Inês; MARTELETO, Regina Maria. Redes sociais: posições dos atores no fluxo da informação. 2012.

VAN DYNE, Linn; PIERCE, Jon L. Psychological ownership and feelings of possession: Three field studies predicting employee attitudes and organizational citizenship behavior. Journal of organizational behavior, v. 25, n. 4, p. 439-459, 2004.

WEBER, Max. The theory of economic and social organization. Trans. AM Henderson and Talcott Parsons. New York: Oxford University Press, 1947.

YANG, Tung-Mou; MAXWELL, Terrence A. Information-sharing in public organizations: A literature review of interpersonal, intraorganizational and inter-organizational success factors. Government Information Quarterly, v. 28, n. 2, p. 164-175, 2011. 